\title{
Pengaruh metode problem based learning dengan teknik mind-mapping terhadap kemampuan penalaran klinis
}

\author{
Gede Arya Bagus Arisudhana ${ }^{1}$, Ni Luh Putu Dewi Puspawati ${ }^{2}$ \\ ${ }^{1}$ Departemen Keperawatan Medikal Bedah, STIKES Bina Usada Bali, Indonesia \\ ${ }^{2}$ Departemen Keperawatan Medikal Bedah, STIKES Wira Medika, Indonesia \\ *Coresponding Author: aryabagus08@gmail.com
}

\begin{abstract}
Abstrak
Pendahuluan: Keberagaman kebutuhan perawatan pasien dan kompleksitas intervensi menuntut mahasiswa keperawatan mahir dalam keterampilan keperawatan dan clinical reasoning untuk mengatasi masalah keperawatan pasien secara efektif. Tujuan penelitian ini untuk mengetahui pengaruh metode problem based learning dengan mind mapping terhadap kemampuan penalaran klinis mahasiswa keperawatan. Metode: Penelitian ini merupakan penelitian pre eksperimen dengan pendekatan one group pretest posttes design, teknik sampling yang digunakan adalah simple random sampling dengan jumlah sampel 62 orang. Data diperoleh menggunakan instrument nursing clinical reasoning assessment tools, analisa data menggunakkan uji Wilcoxon signed rank test. Hasil: Hasil penelitian ini menunjukkan nilai $Z_{\text {hitung }} 6,274$ dan nilai $p=0,000$. Simpulan: Terdapat pengaruh pemanfaatan metode problem based learning dengan mind mapping terhadap kemampuan penalaran klinis mahasiswa keperawatan. Pemanfaatan metode belajar ini dapat digunakan untuk membantu mahasiswa keperawatan memahami masalah keperawatan pasien secara komprehensif.
\end{abstract}

Kata kunci: Clinical reasoning, mind mapping, $P B L$

\section{The effect of problem based learning method with mind-mapping technique on technical reasoning ability}

\begin{abstract}
Introduction: The diversity of patient care needs and the complexity of interventions require nursing students to be proficient in nursing skills and clinical reasoning to effectively address patients' nursing problems. The purpose of this study was to determine the effect of the problem based learning method with mind mapping on nursing students' clinical reasoning abilities. Methods: This research was a pre-experimental research with one group pretest posttest design approach, the sampling technique used was simple random sampling involved 62 students. Data were obtained using nursing clinical reasoning assessment tools then analyzed using the Wilcoxon signed rank test. Results: The results of this study indicated the value of z score was 6.274 and the value of $p=$ 0.000. Conclusions: The use of the problem based learning method with mind mapping influences the clinical reasoning abilities of nursing students. This learning method can be used to facilitate nursing students to comprehensively understand patient nursing problems.
\end{abstract}

Keywords: clinical reasoning, mind mapping, $P B L$

How to Cite: Arisudhana, G.A.B., \& Puspitawati, N.L.P.D. (2019). Pengaruh metode problem based learning dengan teknik mind-mapping terhadap kemampuan penalaran klinis. NURSCOPE: Jurnal Penelitian dan Pemikiran Ilmiah Keperawatan, 5(2), 32-37

\section{PENDAHULUAN}

Profesi keperawatan memiliki tujuan utama memberikan asuhan keperawatan dengan rasa aman, nyaman, dan asuhan yang efektif (Huang, Huang, Lee-Hsieh, \& Cheng, 2018). Pemberian asuhan keperawatan dapat dipengaruhi oleh peningkatan keragaman kebutuhan perawatan pasien dan kompleksitas intervensi. Perubahan pada lingkungan praktik menuntut mahasiswa keperawatan mahir dalam keterampilan keperawatan dan penalaran klinis untuk dapat menyelesaikan kompleksitas masalah keperawatan pasien secara tepat. Beberapa penelitian menunjukkan sebagian 
besar masalah yang dialami perawat dalam menyediakan layanan asuhan keperawatan yang profesional adalah kurangnya kemampuan penalaran klinis (Andersson, Klang, \& Petersson, 2012). Seorang perawat dengan keterampilan penalaran klinis yang baik akan memberikan pengaruh yang positif pada perawatan pasien (Aiken, Clarke, Cheung, Sloane, \& Silber, 2003 dikutip dalam Shellenbarger \& Robb, 2015). Proses penalaran klinis tergantung pada pendekatan berpikir kritis. Penalaran klinis merupakan sebuah proses kognitif dan strategi yang digunakan untuk memahami data pasien, mengidentifikasi dan mendiagnosis masalah pasien, serta meningkatkan kemampuan membuat keputusan klinis yang professional untuk mencapai hasil perawatan yang positif (Forsberg, Ziegert, Hult, \& Fors, 2014).

Mahasiswa keperawatan merupakan seorang pemula dalam melakukan asuhan keperawatan yang komprehensif dan profesional. Meningkatkan kemampuan penalaran klinis dalam pendidikan keperawatan sangat penting dilakukan (Forsberg et al., 2014). Berbagai upaya telah dilakukan untuk meningkatkan kemampuan penalaran klinis degan menerapkan metode pembelajaran questioning, case study, online teaching, interactive learning (Carvalho, Oliveira-Kumakura, \& Morais, 2017), model edutacational learning (Wighus \& Bjørk, 2018) masih belum cukup efektif. Problem based learning (PBL) merupakan sebuah metode yang dapat menciptakan konteks pembelajaran yang menguntungkan bagi pengembangan keterampilan penalaran klinis mahasiswa perawat (Khatiban \& Sangestani, 2014; Merisier, Larue, \& Boyer, 2018). Mahasiswa yang mengikuti metode PBL memiliki kemampuan berpikir kritis yang lebih tinggi dalam mengikuti pelatihan (Jones, 2017). Metode PBL dilakukan dengan membagi mahasiswa menjadi beberapa kelompok diskusi untuk melatih berpikir kritis (Chan, 2017). Pelaksanaan metode PBL dapat dikombinasikan dengan strategi pendekatan mapping (Chan, 2017).

Mind mapping merupakan salah satu model mapping yang dapat digunakan dalam metode PBL. Mind mapping adalah sebuah metode mengubah teks linear menjadi representasi grafis dengan struktur radial dimana konten teks linear ditata ulang dengan menempatkan tema sentral di tengah halaman dengan membentuk beberapa cabang-cabang utama dan sub-cabang kecil lainnya (Merchie \& Keer, 2016). Mind mapping menekankan lebih banyak ide-ide penting, memberikan peluang mencapai solusi masalah secara holistik, serta metode yang mampu mengasah kerja otak kanan dan kiri secara bersamaan (Wycoff, 1991 dikutip dalam Batdi, 2017). Mind mapping dapat digambarkan sebagai teknik pembelajaran yang visual dan fleksibel (Batdi, 2015).

Pemanfaatan mapping yang diimplementasikan pada metode PBL dapat meningkatkan kreativitas dan keaktifan mahasiswa (Chan, 2017). Cara berpikir linear pada mahasiswa tidak lagi memadai pada konteks pembelajaran keperawatan saat ini yang membutuhkan cara berpikir dan belajar eksploratif (Rosciano, 2015). Pendidikan tinggi keperawatan perlu mempertimbangkan metode pembelajaran yang tepat untuk meningkatkan kemampuan critical thingking, clinical reasoning, dan clinical decision sebagai upaya profesionalisme perawat. Penelitian tentang pengaruh metode problem based learning dengan teknik mindmaping terhadap kemampuan penalaran klinis mahasiswa perlu dilakukan untuk meningkatkan keterampilan berpikir mahasiswa perawat khususnya pada masalah keperawatan medikal bedah. Tujuan dari penelitian ini adalah untuk mengetahui pengaruh metode problem based learning dengan teknik mindmaping terhadap kemampuan penalaran klinis mahasiswa perawat pada masalah keperawatan medikal bedah.

\section{METODE}

Penelitian ini merupakan penelitian pre experiment dengan pendekatan one group pretest posttest design. Penelitian ini dilaksanakan di Sekolah Tinggi Ilmu Kesehatan Bina Usada Bali selama 12 minggu. Sampel dalam penelitian ini adalah mahasiswa program S1 keperawatan. Teknik sampling yang digunakan dalam penelitian ini adalah teknik simple random sampling, dimana peneliti memberikan kesempatan yang sama pada anggota populasi untuk menjadi sampel. Jumlah sampel dalam 
penelitian ini adalah 62 orang. Data kemampuan penalaran klinis diperoleh melalui pengisian instrumen Nursing Clinical Reasoning Assessment Tools yang dikembangkan oleh peneliti berdasarkan instrumen clinical reasoning inventory. Analisa data digunakan wilcoxon signed rank test

\section{HASIL DAN PEMBAHASAN}

1. Kemampuan Penalaran Klinis Sebelum Intervensi

Tabel 1. Kemampuan penalaran klinis mahasiswa perawat sebelum intervensi metode problem based learning dengan mind mapping

\begin{tabular}{cclllc}
\hline Variabel & Mean & Median & Min-Max & $\begin{array}{c}\text { Std. } \\
\text { Deviasi }\end{array}$ & 95\%Cl \\
\hline Kemampuan Penalaran Klinis & 68.69 & 70 & $52-85$ & 7.863 & $66.70-70.69$ \\
\hline
\end{tabular}

Tabel 1. Menunjukkan kemampuan clinical reasoning mahasiswa perawat sebelum mengikuti pembelajaran menggunakan metode problem based learning dengan mind mapping memiliki rata-rata 68.69, nilai tengah (median) 70, serta nilai minimal 52 dan nilai maksimal 85.

2. Kemampuan Penalaran Klinis Setelah Intervensi

Tabel 2. Kemampuan penalaran klinis mahasiswa perawat setelah intervensi metode problem based learning dengan mind mapping

\begin{tabular}{cclllc}
\hline Variabel & Mean & Median & Min-Max & $\begin{array}{c}\text { Std. } \\
\text { Deviasi }\end{array}$ & 95\%Cl \\
\hline Kemampuan Penalaran Klinis & 75.08 & 77 & $57-92$ & 7.106 & $73.28-76.89$ \\
\hline
\end{tabular}

Tabel 2. Menunjukkan kemampuan clinical reasoning mahasiswa perawat sebelum sebelum mengikuti pembelajaran menggunakan metode problem based learning dengan mind mapping mengalami peningkatan rata-rata 75.08, nilai tengah (median) 77, serta nilai minimal 57 dan nilai maksimal 92.

3. Pengaruh Metode Problem Based Learning dengan Mind Mapping terhadap Kemampuan Penalaran Klinis Mahasiswa Perawat

Tabel 3. Analisis pengaruh metode problem based learning dengan mind mapping terhadap kemampuan penalaran klinis mahasiswa perawat

\begin{tabular}{llllll}
\hline Variabel & $\begin{array}{c}\text { Negative } \\
\text { Rank }\end{array}$ & $\begin{array}{c}\text { Positive } \\
\text { Rank }\end{array}$ & Ties & Z & p-value \\
\hline $\begin{array}{l}\text { Kemampuan Penalaran Klinis } \\
\text { Post-Pre }\end{array}$ & 4 & 56 & 2 & 6.274 & 0.000 \\
\hline
\end{tabular}

Tabel 3. menunjukkan terdapat 4 responden dengan negative rank (nilai post test < pre test), 56 positive rank (nilai post test > pre test), dan terdapat 2 ties (nilai post test $=$ pre test). Hasil uji Wilcoxon menunjukkan nilai $Z$ hitung 6.274 dengan nilai $p=0.000$ pada tingkat kemaknaan $\alpha=0.05$.

Kemampuan penalaran klinis merupakan sebuah proses menentukan solusi dari sebuah masalah yang dapat digunakan oleh tenaga kesehatan. Metode PBL dan mind mapping merupakan metode pembelajaran yang bertujuan menumbuhkan keterampilan penalaran klinis (de Menezes, Corrêa, e Silva, \& da Cruz, 2015; Rochmawati \& Wiechula, 2010). Hasil penelitian ini menunjukkan terdapat pengaruh metode $\mathrm{PBL}$ dengan mind mapping terhadap kemampuan penalaran klinis mahasiswa perawat yang dibuktikan dengan nilai $p<0.05$. Hal ini sejalan dengan penelitian yang dilakukan Hung dan Lin, menjelaskan PBL dapat meningkatkan kemampuan penalaran klinis dan membantu mahasiswa memahami konsep lebih banyak (Hung \& Lin, 2015). Problem based learning merupakan metode belajar yang banyak digunakan dalam pendidikan keperawatan untuk meningkatkan 
kemampuan mahasiswa dalam mengembangkan keterampilan pemecahan masalah dan penalaran klinis melalui pemikiran kritis (Murphy, Hartigan, Walshe, Flynn, \& O'Brien, 2011), serta melalui penggunaan mind mapping pada metode PBL (Daley \& Torre, 2010).

Kemampuan penalaran klinis mahasiswa keperawatan memiliki rata-rata 68.69 , nilai tengah 70 , serta nilai minimal 52 dan nilai maksimal 85 sebelum mengikuti kuliah menggunakan metode problem based learning dengan mind mapping yang ditunjukkan pada table 1 . Tabel 2 menunjukkan kemampuan penalaran klinis mahasiswa perawat mengalami peningkatan rata-rata 75.08 , nilai tengah 77 , serta nilai maksimal 92. Penalaran klinis merupakan konsep utama yang mendukung kurikulum pendidikan keperawatan (Levett-jones et al., 2010). Perawat dengan kemampuan penalaran klinis yang buruk akan mengakibatkan kegagalan dalam melakukan deteksi menurunnya kondisi pasien menjadi lebih buruk sehingga mengakibatkan kegagalan dalam pengambilan keputusan untuk menyelamatkan pasien. Penalaran klinis meliputi tindakan memproses sebuah informasi mengenai masalah pasien, pemahaman masalah pasien, perencanaan dan pelaksanaan intervensi yang tepat, mengevaluasi rencana keperawatan, serta merefeksikan proses penalaran klinis (Levett-jones et al., 2010).

Sebagai upaya untuk dapat mengajarkan dan meningkatkan kemampuan penalaran klinis pada mahasiswa keperawatan, seorang tenaga pengajar harus dapat membantu mahasiswa mengembangkan kemampuan dalam memahami sifat situasi pada pasien dengan analisa yang relevan dan tindakan keperawatan yang tepat. Pemanfaatan mind-mapping pada problem based learning sebagai alat untuk membantu mahasiswa meningkatkan pengetahuan. Hal ini sejalan dengan penelitian yang dilakukan Riyanto \& Subroto (2017), menjelaskan bahwa keterampilan berpikir kritis mahasiswa dengan model PBL menggunakan mind-mapping lebih baik jika dibandingkan dengan mahasiswa dengan model pembelajaran konvensional (Riyanto \& Subroto, 2017).

Pada metode PBL dengan mind-mapping memberikan mahasiswa peluang untuk dapat mengembangkan keterampilan berpikir kritis melalui proses pemecahan masaslah yang kompleks, sehingga keterampilan penalaran klinis seperti analisa, interpretasi, evaluasi, dan iferensiasi menjadi lebih baik (Ersoy \& Başer, 2014). Aplikasi PBL dengan metode mind-mapping dapat membuat pembelajaran dalam keperawatan menjadi lebih menarik, menantang, dan lebih berarti sehingga dapat meningkatkan hasil belajar mahasiswa. Sejalan dengan Jain (2015) menjelaskan mind-mapping lebih efektif dalam membantu mahasiswa memahami konsep pengetahuan secara rinci (Jain, 2015). Mind-mapping dapat membantu meningkatkan memori jangka panjang serta membantu mahasiswa mengingat lebih banyak kata kunci pada suatu masalah yang dipelajari.

Metode PBL dengan mind-mapping mampu mneingkatkan kualitas pembelajaran mahasiswa melalui proses berpikir. Sejalan dengan penelitian Novita, Bukit, \& Sirait, (2018) yang menjelaskan mindmapping mampu meningkatkan kualitas pembelajaran karena konsep pembelajaran menjadi mudah dipelajari. Penelitian lain menyebutkan PBL menggunakan mind-mapping dapat meningkatkan keterampilan pemecahan masalah mahasiswa yang disebabkan mudahnya mahasiswa mengingat konsep materi yang diajarkan (Arahmat, Suratno, \& Wahono, 2017). Pemanfaatan mind-mapping dalam PBL akan menggambarkan sebuah variasi yang cukup besar dalam struktur mind-mapping. Hal ini dapat menjadi tolak ukur tingkat diskusi yang terjadi selama sesi PBL dan kedalaman pengetahuan serta pemahaman yang dicapai masing-masing mahasiswa. Pemanfaatan mind mapping dalam metode $P B L$ juga memberikan suatu pengalaman belajar yang menarik bagi pendidik keperawatan.

\section{SIMPULAN DAN SARAN}

Pada penelitian ini dapat disimpulkan terdapat pengaruh metode problem based learning dengan mind mapping terhadap kemampuan penalaran klinis mahasiswa keperawatan. Penalaran klinis merupakan komponen utama dalam pendidikan keperawatan. Perawat yang tidak memiliki penalaran 
klinis yang baik dapat mengakibatkan kesalahan dalam pengambilan keputusan pada perawatan pasien.

Penelitian ini memiliki beberapa keterbatasan, dimana pengajar keperawatan harus memahami dan memperhatikan kemampuan mahasiswa dalam menguasai masalah kesehatan yang terjadi pada pasien. Peneliti belum membandingkan kemampuan mahasiswa keperawatan berdasarkan stratifikasi tingkat semester, sehingga hanya memberikan gambaran pada mahasiswa tingkat 3 . Penelitian selanjutnya dapat dikaji penggunaan metode lainnya dalam meningkatkan kemampuan penalaran klinis dan berpikir kritis mahasiswa.

\section{DAFTAR PUSTAKA}

Aiken, L. H., Clarke, S. P., Cheung, R. B., Sloane, D. M., \& Silber, J. H. (2003). Educational Levels of Hospital Nurses and Surgical Patient Mortality. JAMA, 290(12), 1617-1623.

Andersson, N., Klang, B., \& Petersson, G. (2012). Differences in clinical reasoning among nurses working in highly specialised paediatric care. Journal of Clinical Nursing, 21(5-6), 870-879.

Arahmat, Y., Suratno, S., \& Wahono, B. (2017). The Effect Of Problem Based Learning Model With Mind Mapping Technique On Biology Learning Achivement. Pancaran Pendidikan, 6(2), 125-132.

Batdi, V. (2015). A Meta-analysis Study of Mind Mapping Techniques and Traditional Learning Methods A Meta-analysis Study of Mind Mapping Techniques. The Anthropologist, 20(1-2), 6268.

Carvalho, E. C. de, Oliveira-Kumakura, A. R. de S., \& Morais, S. C. R. V. (2017). Clinical reasoning in nursing: teaching strategies and assessment tools. Revista Brasileira de Enfermagem, 70(3), 662668.

Chan, Z. C. Y. (2017). A qualitative study on using concept maps in problem-based learning. Nurse Education in Practice, 24, 70-76.

Daley, B. J., \& Torre, D. M. (2010). Concept maps in medical education: An analytical literature review. Medical Education, 44(5), 440-448.

de Menezes, S. S. C., Corrêa, C. G., e Silva, R. de C. G., \& da Cruz, D. de A. M. L. (2015). Clinical reasoning in undergraduate nursing education: A scoping review. Revista Da Escola de Enfermagem, 49(6), 1032-1039.

Ersoy, E., \& Başer, N. (2014). The Effects of Problem-based Learning Method in Higher Education on Creative Thinking. Procedia - Social and Behavioral Sciences, 116, 3494-3498.

Forsberg, E., Ziegert, K., Hult, H., \& Fors, U. (2014). Clinical reasoning in nursing, a think-aloud study using virtual patients - A base for an innovative assessment. Nurse Education Today, 34(4), 538542.

Huang, H.-M., Huang, C., Lee-Hsieh, J., \& Cheng, S. (2018). Establishing the competences of clinical reasoning for nursing students in Taiwan: From the nurse educators' perspectives. Nurse Education Today, 66(7), 110-116.

Hung, C. H., \& Lin, C. Y. (2015). Using concept mapping to evaluate knowledge structure in problembased learning. BMC Medical Education, 15(1), 1-9.

Jain, D. S. (2015). The comprehensive Study of how Mind mapping Technique Helps to Understand Concepts and Ideas in Science Teaching. International Journal of Scientific and Research 
Publications, 5(12), 284-286.

Jones, G. H. (2017). Mental health student nurses' satisfaction with problem-based learning: a qualitative study. The Journal of Mental Health Training, Education and Practice, 12(2), 77-89.

Khatiban, M., \& Sangestani, G. (2014). Nurse Education in Practice The effects of using problem-based learning in the clinical nursing education on the students' outcomes in Iran: A quasiexperimental study. Nurse Education in Practice, 30(1), 1-6.

Levett-jones, T., Hoffman, K., Dempsey, J., Jeong, S. Y., Noble, D., Anne, C., ... Hickey, N. (2010). Nurse Education Today The ' five rights' of clinical reasoning : An educational model to enhance nursing students ' ability to identify and manage clinically ' at risk' patients. Nurse Education Today, 30 , 515-520.

Merchie, E., \& Keer, H. Van. (2016). Learning strategies and performance ? Department of Educational Studies, Ghent University , Belgium. Contemporary Educational Psychology, 46(7), 128-147.

Merisier, S., Larue, C., \& Boyer, L. (2018). How does questioning influence nursing students' clinical reasoning in problem-based learning? A scoping review. Nurse Education Today, 65(6), 108-115.

Murphy, S., Hartigan, I., Walshe, N., Flynn, A. V., \& O’Brien, S. (2011). Merging Problem-Based Learning and Simulation as an Innovative Pedagogy in Nurse Education. Clinical Simulation in Nursing, $7(4)$.

Novita, D., Bukit, N., \& Sirait, M. (2018). The Effect of Problem-Based Learning Models Using Mind Map to Improve Critical Thinking and Problems Solving Skill of Student. In 3rd Annual International Seminar on Transformative Education and Educational Leadership (AISTEEL 2018) (Vol. 200, pp. 17-21).

Riyanto, Y., \& Subroto, W. T. (2017). Application of PBL with Mind Mapping Method to Increase Cognitive Learning Result of Social Study in Fourth Grade Students. In 1st International Conference on Education Innovation (ICEI) (pp. 799-803). Surabaya: Universitas Negeri Surabaya.

Rochmawati, E., \& Wiechula, R. (2010). Education strategies to foster health professional students' clinical reasoning skills. Nursing and Health Sciences, 12(2), 244-250.

Rosciano, A. (2015). The effectiveness of mind mapping as an active learning strategy among associate degree nursing students. Teaching and Learning in Nursing, 10(2), 93-99.

Shellenbarger, T., \& Robb, M. (2015). Technology-Based Strategies for Promoting Clinical Reasoning Skills in Nursing Education. Nurse Educator, 40(2), 79-82.

Wighus, M., \& Bjørk, I. T. (2018). An educational intervention to enhance clinical skills learning: Experiences of nursing students and teachers. Nurse Education in Practice, 29(3), 143-149. 